\title{
REFRACTORY ANEMIA AND PANCYTOPENIA AS PRESENTATIONS OF FALCIPARUM MALARIA IN POPULATION OF KHYBER PAKHTUNKHWA, PAKISTAN
}

\author{
Zafar Hayat', Inam Ullah², Khizar Hayat ${ }^{2}$, Hashimuddin Azam Khan², Fazle Raziq ${ }^{3}$, Habibullah Khan ${ }^{4}$ \\ ${ }^{1}$ Department of Medicine, Kabir Medical College, Gandhara University, Peshawar, Departments of ${ }^{2}$ Medicine \& \\ ${ }^{3}$ Pathology, Khyber Teaching Hospital, Peshawar, ${ }^{4}$ Rauf Medical Centre, D.I.Khan, Pakistan
}

\begin{abstract}
Background: Falciparum malaria is not an uncommon infection in population of Khyber Pakhtunkhwa, Pakistan. Apart from its classical presentation, it may present with refractory anemia or pancytopenia. The objective of this study was to determine frequency of refractory anemia and pancytopenia as presentations of falciparum malaria in population of Khyber Pakhtunkhwa, Pakistan.

Material \& Methods: This descriptive study was conducted at the Department of Medicine, Khyber Teaching Hospital, Peshawar, Pakistan, over the years 2011 to 2014. A detailed history, clinical examination, and pertinent laboratory tests were performed for a sample of 200 cases of falciparum malaria. All patients were treated with antimalarial drugs and followed-up for eight weeks.

Results: Out of 200 patients with falciparum malaria, 85 (42.5\%) were males and 115 (57.5\%) females. The age ranged from 15 to 55 years. Out of these 200 patients, frequency of refractory anemia was 175 (87.5\%) and frequency of pancytopenia was 25 (12.5\%). Among 175 cases, 125 (71.43\%) were smear positive for $P$. falciparum and $50(28.57 \%)$ were positive on rapid antigen tests (RATs). In 25 (12.5\%) patients with pancytopenia, the smear for malaria and RATs were positive only in 5 (20\%) patients. In remaining 20 (80\%) cases, bone marrow examination revealed $P$. falciparum in all cases. All patients dramatically responded to treatment with antimalarials and supportive care including hematinics.
\end{abstract}

Conclusion: Plasmodium falciparum should be considered in cases of prolonged fever with refractory anemia or pancytopenia in the malaria endemic areas, even with negative smear and rapid antigen tests. Bone marrow examination is mandatory for diagnosis in such cases.

KEY WORDS: Malaria; Falciparum malaria; Plasmodium falciparum; Anemia; Refractory anemia; Pancytopenia; Splenomegaly.

This article may be cited as: Hayat Z, Ullah I, Hayat K, Khan HA, Raziq F, Khan H. Refractory anemia and pancytopenia as presentations of falciparum malaria in population of Khyber Pakhtunkhwa, Pakistan. Gomal J Med Sci 2019 Jul-Sep; 17 (3):75-80. https://doi.org/10.46903/gjms/17.03.2027

\section{INTRODUCTION}

Falciparum malaria is not an uncommon infection in population of Khyber Pakhtunkhwa, Pakistan. It classically presents with high grade fever, rigors, and splenomegaly. Anemia is also a well-known feature but at times it may present with severe anemia refractory to treatment or pancytopenia. ${ }^{1,2}$

\section{Corresponding Author:}

Prof. Zafar Hayat

Department of Medicine, Kabir Medical College,

Gandhara University, Peshawar

E-mail: zafarhayat517@gmail.com

Date Submitted: 09-01-2019

Date Revised: 22-04-2019

Date Accepted: $\quad$ 15-05-2019
Invasion of host erythrocytes (RBCs) by PF and release of merozoites during schizogony do result in intravascular hemolysis; but this alone cannot explain the gross anemia which these patients may develop. ${ }^{2,3}$ Analysis of clinical data from endemic areas have shown that up to 12 uninfected RBCs are lost for every infected one.,4 Other suggested mechanisms in the development of severe malarial anemia from the literature review include, the RBCs destruction due to macrophage activation in the spleen, immune mediated hemolysis, and oxidative stress. ${ }^{5-7}$ Other host factors include the cytokines and growth factors, like tumor necrosis factor- $\square$ (TNF- $\square$ ) and interferon- $\square$ (IFN- $\square$ ) which may cause dyserythropoeisis, decreased production of erythropoeitin, and erythrophagocytosis in the bone marrow (BM) ${ }^{8-10}$ Also, the cytokines TNF- $\square$ and IFN- $\square$ 
suppress the BM hematopoeisis by over-production of nitric oxide (NO) which can inhibit the enzyme methionine synthetase leading to functional vitamin B12 deficiency which may lead to pancytopenia and megaloblastic anemia due to maturation arrest. ${ }^{11-15}$ On the other hand high, levels of interleukin-10 (IL-10) produced by T-helper cells prevent the development of anemia and its low levels have been reported to cause anemia. ${ }^{16}$

Interestingly, in the areas of endemic malaria, patients with fever and severe anemia often have negative malarial parasite (MP) by microscopy on Giemsa-stained smears, but their leucocytes commonly contain detectable malarial pigment, which may be detected by the Rapid Antigen Tests (RATs). ${ }^{17,18}$

Peripheral cytopenia and BM suppression are caused by the sequestration syndrome associated with heavy $P$. falciparum parasitemia. The $P$. falciparum by cyto-adherence attach to the endothelial lining of micro-circulation (hence the higher yield of positive MP smears for falciparum malaria from finger-prick as compared to venous blood). Sequestration also leads to local thrombosis, BM edema and necrosis thus causing BM suppression. In such cases both the peripheral blood MP smears and the RATs may be negative and the only evidence to the diagnosis of falciparum malaria may be achieved on BM examination. ${ }^{19-23}$

The rationale of this study was that although MP smears were the gold standard test for the diagnosis of malaria but in Pakistan, we come across patients of malaria with refractory anemia and pancytopenia. Repeated MP smears may be negative in many of these cases and other approaches like rapid antigen tests or bone marrow examination may guide us to reach the proper diagnosis.

The objective of this study was to determine the frequency of refractory anemia and pancytopenia as presentations of falciparum malaria in population of Khyber Pakhtunkhwa, Pakistan.

\section{Operational definitions}

Refractory anemia: a rapidly developing anemia with $\mathrm{Hb}<9 \mathrm{~g} / \mathrm{dl}, \mathrm{PCV}<30 \%$, RBC count $<2.5$ million/ $\mathrm{cm}^{3}$, reticulocyte count $<1 \%$, and no improvement despite treatment with hematinics and packed cell transfusions for two weeks.

Pancytopenia: It was defined as $\mathrm{Hb}<9 \mathrm{~g} / \mathrm{dl}$, TLC $<4,000 / \mu \mathrm{L}$ and platelet count $<150,000 / \mu \mathrm{L}$.

\section{MATERIAL AND METHODS}

Design, Settings \& Duration: This descriptive study was conducted at the Department of Medicine, Khyber Teaching Hospital, Peshawar, Pakistan, over the years 2011 to 2014. The proposal was approved by the Ethical Review Committee of Khyber Medical College and Khyber Teaching Hospital, Peshawar.

Population, Sample size, Technique \& Selection:
A population of 5000 patients with falciparum malaria was assumed to reside in Khyber Pakhtunkhwa province, the catchment area of Khyber Teaching Hospital, Peshawar. A sample size of 200 was calculated through Raosoft ${ }_{\circledast}$; an online sample size calculator, with margin of error $2.96 \%, 95 \% \mathrm{CL}$, prevalence of refractory anemia in falciparum malaria $1 \%$ and population size of 5000 patients with falciparum malaria. The sampling technique was consecutive non-probability.

All the patients presenting with fever for 2-6 weeks, splenomegaly, and refractory anemia or pancytopenia were eligible for inclusion. Cases of anemia with known causes of fever like typhoid fever (blood culture and/or typhidot IgM positive), organ-specific fevers like pneumonia, pleural effusion, miliary tuberculosis, infective endocarditis, urinary tract infection, auto-immune diseases like systemic lupus erythematosus, rheumatoid arthritis, immunodeficiency states like HIV infection, those on immunosuppressive drugs, hematological malignancies, congenital anemias like thalassemia, sickle cell disease, anemia of chronic renal failure, and cases of idiopathic/ drug-induced BM suppression were excluded from the study.

Conduct of Procedure \& Intervention: A detailed clinical history was taken including onset and duration of fever, history of recent bleeding (gut, urinary, or menorrhagia in females), family history of congenital anemia, and drug history. A thorough clinical examination was undertaken to record pallor, purpura or mucosal bleed. Lymph node regions were examined to exclude lymphadenopathy (for lymphoma /leukemia). Abdominal examination was undertaken to document splenomegaly and to exclude hepatomegaly \& any abnormal mass or ascites, chest examination to exclude pneumonia or pleural effusion, and heart examination to exclude any murmurs for infective endocarditis. Retinal fundoscopic examination was performed to document or exclude any retinal hemorrhages, Rothspots or leukemic deposits.

Laboratory tests were divided into two parts. Part I investigations included; (1) Tests to exclude other causes of fever and anemia or pancytopenia: Blood cultures/ typhidot test were done to exclude typhoid fever and septicemia. Urine cultures were taken in selected cases of UTI. X-ray chest was done in all cases to exclude pneumonia, plural effusion, pulmonary or miliary tuberculosis. Abdominal ultrasound and/ or CT scan were done to exclude abdominal lymphadenopathy or ascites (tuberculosis, lymphoma), liver abscess, pelvic inflammatory disease (in females) and renal sepsis. Stool tests were performed for hookworm infestation. In all cases of pancytopenia, dengue profile (Dengue NS1 antigen and IgM and IgG antibodies) were done to exclude dengue fever. (2) Tests to identify P. falciparum: thick 
\& thin peripheral blood smears (from venous blood and finger prick). Rapid Antigen Tests to identify $P$. falciparum antigens: Two Rapid Antigen Tests (based on two soluble malarial cell-wall antigens) were performed in cases where MP was reported negative on peripheral blood smears. The tests included: NOW ${ }^{\circledR}$ Malaria Test (Binax, Inc., Portland, ME, USA) based on detection of histidine rich protein 2 (HRP2) and aldolase that can remain positive for weeks following treatment of infection, and Optimal ${ }^{\circledR}$ (DiaMed AG, Cressier, Switzerland) which detects parasite derived lactate dehydrogenase (pLDH) that is positive only in the presence of live parasites. ${ }^{24}$ Part 2 investigations included: (1) Tests to document and assess the degree of anemia in patients with refractory anemia including full blood count (FBC), reticulocyte count, peripheral blood smears for RBC and WBC morphology, serum iron and ferritin levels, red cell folate and vitamin $\mathrm{B}_{12}$ levels. (2) BM examination (aspiration and trephine biopsy) in cases of pancytopenia where both peripheral smears and RATs were negative to document BM suppression, to identify P. falciparum, and to exclude other causes of BM suppression like leukemias or myelodysplastic syndromes.

All patients were treated with antimalarials; IV Artisunate $2.5 \mathrm{mg} / \mathrm{kg}$ body weight and Mefloquine for six days along with supportive treatment and hematinics (iron supplements, folic acid, vitamin $\mathrm{B}_{12}$ ) and packed cells transfusions where indicated. All had uneventful recovery and there was complete defervescence within 10 to 14 days. Anemia and pancytopenia were rapidly corrected to normal within 8 weeks.

In patients with refractory anemia, the peripheral blood smears for PF malaria were reported negative in the previously positive cases. In 20 patients with pancytopenia, the pancytopenia reverted to normal in all cases within 8 weeks. Repeat BM examinations after 8 weeks post-treatment were reported free of MP and disappearance of dyserythropoeisis and erythrophagocytosis.

Data Collection \& Analysis Plan: Presence of refractory anemia (yes/ no), presence of pancytopenia (yes/ no), hemoglobin level (g/dl), packed cells volume (\%), erythrocyte count (million $/ \mu \mathrm{L}$ ), reticulocyte count (\%), total leucocyte count (cells $/ \mu \mathrm{L}$ ), polymorphonuclear cells $(\%)$, platelet count (cells $/ \mu \mathrm{L}$ ) were research variables. Presence of refractory anemia and presence of pancytopenia were measured on nominal scale and analyzed by frequency and percentage. All the other variables were measured on ratio (numeric) scale and were analyzed by mean.

\section{RESULTS}

Out of 200 patients with falciparum malaria, 85 (42.5\%) were males and 115 (57.5\%) females. The age ranged from 15 to 55 years. Out of 200 patients with falciparum malaria, the frequency of refractory anemia was 175 (87.5\%) and the frequency of pan- cytopenia was 25 (12.5\%).

The mean pre and post treatment values of hematologic findings in falciparum malaria presenting with refractory anemia are shown in Tables 1. All these showed improvement following the use of antimalarials.

Table 1: Mean pre and post treatment hematologic findings in falciparum malaria presenting with refractory anemia $(n=175)$.

\begin{tabular}{|l|c|c|}
\hline $\begin{array}{l}\text { Hematologic } \\
\text { Parameter }\end{array}$ & Pre-treatment & Post-treatment \\
\hline $\begin{array}{l}\text { Hemoglobin } \\
\text { (g/dl) }\end{array}$ & 7.0 & 12.0 \\
\hline $\begin{array}{l}\text { Packed cells } \\
\text { volume }\end{array}$ & $30 \%$ & $42 \%$ \\
\hline $\begin{array}{l}\text { Erythrocyte count } \\
\text { (million/ } \mu \mathrm{L})\end{array}$ & 2.3 & 4.2 \\
\hline $\begin{array}{l}\text { Reticulocyte } \\
\text { count }\end{array}$ & $1.2 \%$ & $2 \%$ \\
\hline
\end{tabular}

The mean pre and post treatment values of hematologic findings in falciparum malaria presenting with pancytopenia are shown in Tables 2. All these showed improvement following the use of antimalarials.

Table 2: Mean pre and post treatment hematologic findings in falciparum malaria presenting with pancytopenia $(n=25)$.

\begin{tabular}{|l|c|c|}
\hline Parameter & Pre-treatment & Post-treatment \\
\hline $\begin{array}{l}\text { Hemoglobin } \\
(\mathrm{g} / \mathrm{dl})\end{array}$ & 5.0 & 11.0 \\
\hline $\begin{array}{l}\text { Erythrocyte } \\
\text { count (million } / \mu \mathrm{L})\end{array}$ & 1.2 & 4.0 \\
\hline $\begin{array}{l}\text { Reticulocyte } \\
\text { count }\end{array}$ & $<1.0 \%$ & $2 \%$ \\
\hline $\begin{array}{l}\text { Total leucocyte } \\
\text { count } \\
\text { (cells } / \mu \mathrm{L} \text { ) }\end{array}$ & 1,800 & 4,500 \\
\hline $\begin{array}{l}\text { Polymorphonu- } \\
\text { clear cells }\end{array}$ & $33 \%$ & $55 \%$ \\
\hline $\begin{array}{l}\text { Platelet count } \\
\text { (cells } / \mu \mathrm{L} \text { ) }\end{array}$ & 55,000 & 155,000 \\
\hline
\end{tabular}

In patients with refractory anemia, 125 (71.43\%) were reported positive for $\mathrm{PF}$ on peripheral blood smears. In the remaining $50(28.57 \%)$ smear negative patients, the Rapid Antigen Tests were positive and thus BM examination was not required in these cases. (Table 3 \& Fig. 1) 
Table 3: Results of laboratory tests to identify $P$. falciparum malaria as a cause of fever and refractory anemia or pancytopenia $(n=200)$

\begin{tabular}{|c|c|c|c|c|c|}
\hline \multirow{3}{*}{ Presentation } & \multirow{3}{*}{ Count \& \%age } & \multicolumn{4}{|c|}{ Laboratory tests to identify PF malaria } \\
\hline & & \multicolumn{2}{|c|}{ MP smear } & \multirow{2}{*}{$\begin{array}{l}\text { Positive RATs in } \\
\text { MP negative }\end{array}$} & \multirow{2}{*}{$\begin{array}{l}\text { PF detection on BM in MP \& } \\
\text { RATs negative }\end{array}$} \\
\hline & & Positive & Negative & & \\
\hline $\begin{array}{l}\text { Refractory } \\
\text { anemia }\end{array}$ & $\begin{array}{c}175 \\
(87.5 \%)\end{array}$ & $125(71.42 \%)$ & $\begin{array}{c}50 \\
(28.57 \%)\end{array}$ & $\begin{array}{c}50 \\
(100 \%)\end{array}$ & Not indicated \\
\hline Pancytopenia & $\begin{array}{c}25 \\
(12.5 \%)\end{array}$ & $\begin{array}{c}5 \\
(20 \%)\end{array}$ & $\begin{array}{c}20 \\
(80 \%)\end{array}$ & $\begin{array}{c}0 \\
(0 \%)\end{array}$ & $\begin{array}{c}20 \\
(100 \%)\end{array}$ \\
\hline
\end{tabular}

$\mathrm{BM}=$ Bone marrow, $\mathrm{MP}=$ Malaria Parasite, $\mathrm{PF}=$ Plasmodium falciparum, RATs $=$ Rapid Antigen Tests.

A

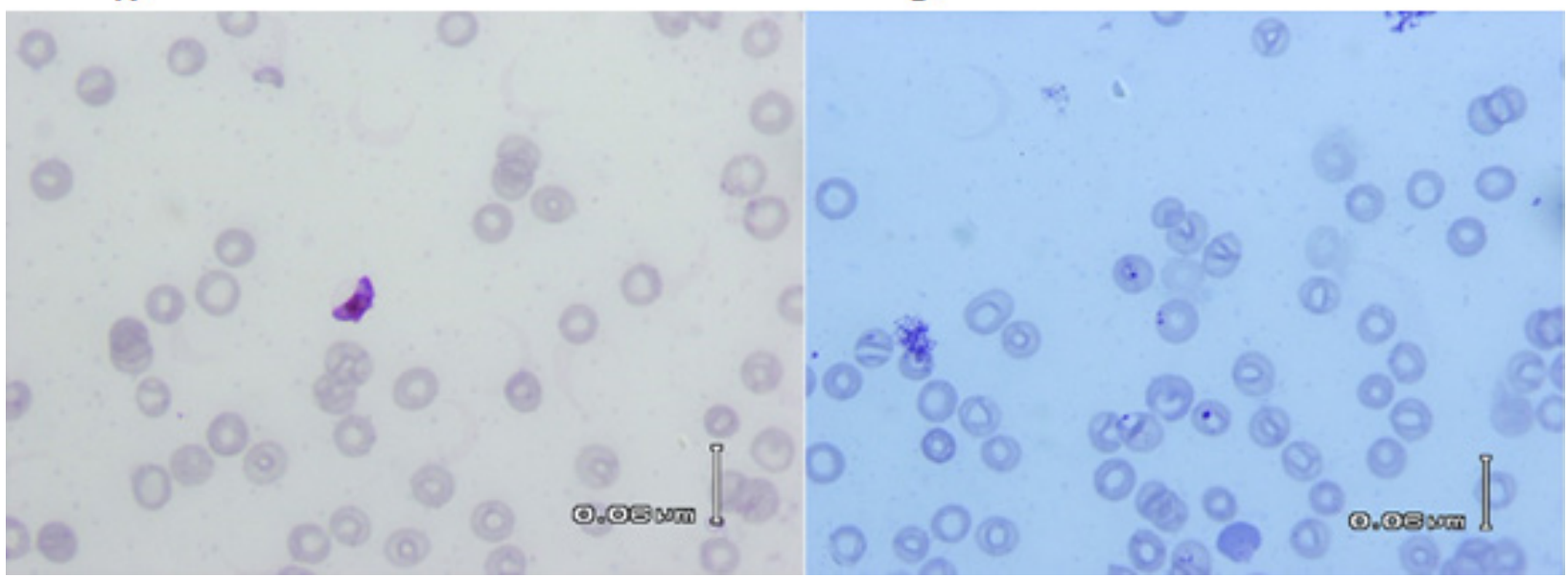

Figure 1: Giemsa stained peripheral blood smears showing (A) gametocyte and (B) trophozoites of Plasmodium falciparum.

In patients with pancytopenia, only $5(20 \%)$ were reported smear positive for MP. The RATs were also reported positive in these five cases. In the remaining $20(80 \%)$ cases both the peripheral blood smears and RATs were negative for $P$. falciparum. (Table 3) BM examination was performed in these cases that revealed trophozoites and gametocytes of $P$. falciparum in all the 20 cases. The BM was also reported to have edema, necrosis, dyserythropoeisis and erythrophagocytosis.

\section{DISCUSSION}

Anemia is a common and recognized complication of falciparum malaria. ${ }^{1}$ Many pathophysiologic mechanisms have been described to explain the degree, and course of anemia in these patients. ${ }^{4}$ In malaria endemic areas, it may be additionally complicated by parasitic infestations, and deficiency of iron, folic acid, vitamin $\mathrm{B}_{12}$ and other nutrients.

The present study confirms that $P$. falciparum malaria might present with fever and refractory anemia or pancytopenia. Aggarwal et al. ${ }^{24}$ reported the case of a child with refractory anemia and pancytopenia having repeatedly negative MP smears which turned out to be a case of falciparum malaria with BM full of $P$. falciparum with the conclusion that malaria should always be considered as the cause of anemia in endemic areas even in the absence of classical symptoms and negative reports of MP smears.

In our study the RATs aided in the diagnosis of falciparum malaria in the 50 smear-negative patients with fever and refractory anemia. Although peripheral smear is the gold standard test for the diagnosis of malaria, the RATs detection methods may be superior to microscopy in the diagnosis of malarial anemia in certain circumstances. These results are in accordance with many international studies. Piper et al. ${ }^{22}$ described in their study on evaluation of Plasmodium lactate dehydrogenase (pLDH) based RATs to be both sensitive and practical in detection of all human Plasmodium infections. Kurtzhals et al. ${ }^{17}$ and Nkrumah et al. ${ }^{18}$ reported that children living in the malaria endemic areas are usually hospitalized for fever with severe anemia. These patients often have negative MP smears, but their leucocytes contain detectable malarial pigment, and hence the diagnosis of falciparum malaria may be established by RATs only in these patients.

In our study, in 20 patients with fever and pancytopenia where both the MP smears and RATs were reported negative, BM examination was reported positive for 
P. falciparum for all these cases. BM examination can be considered to exclude or confirm the possibility of malaria in patients with pyrexia of unknown origin and pancytopenia with negative results on serial MP smears and RATs. In a study by Mirdhaet et al. ${ }^{19}$, they examined BM for the diagnosis of malaria in patients with prolonged fever and resulted in a diagnosis of malaria in $6.6 \%$ of patients. The diagnostic efficacy of BM for the evidence of malaria was useful in febrile individuals for whom the diagnosis was otherwise unknown.

In our study the MP smear positivity yield was higher in contrast to the literature review. This could be because the MP smears in our patients were made from both the venous blood and finger prick. Most of the $P$. falciparum parasites are adhering to the endothelium of the microcirculation by cytoadherence or sequestration and therefore the finger prick blood may give higher yield as compared to the venous blood. This phenomenon was also described by Autino et al. ${ }^{23}$ in their study.

Regarding response to treatment, consistent with the literature, all our patients responded dramatically to antimalarial treatment. The fever subsided within 10 to 14 days and anemia got rapidly corrected to normal within eight weeks. Repeat peripheral blood smears were reported negative in the previously positive cases. The peripheral pancytopenia also reverted to normal and repeat BM examinations post-treatment were reported free of malarial parasites with recovery of $\mathrm{BM}$. These findings are consistent with many other studies. ${ }^{25,26}$

\section{CONCLUSION}

Plasmodium falciparum should be considered in all cases of prolonged fever with refractory anemia or pancytopenia in the malaria endemic areas, even with negative smear and rapid antigen tests. Bone marrow examination is mandatory for the diagnosis of falciparum malaria in such cases.

\section{REFERENCES}

1. Ghosh K. Mechanism of anemia in malaria and its management, Indian J Hematol Blood Tranfus 2003; 21:128-30.

2. Breman JG, Egan A, Keusch GT. The intolerable burden of malaria: a new look at the numbers. Am J Trop Med Hyg 2001; 64:iv-vii. https://doi. org/10.4269/ajtmh.2001.64.iv

3. Jakeman GN, Saul A, Hogarth WL, Collins WE. Anaemia of acute malaria infections in non-immune patients primarily results from destruction of uninfected erythrocytes. Parasitology 2000; 119:127-33. https://doi.org/10.1017/ S0031182099004564

4. Price RN, Simpson JA, Nosten F, Luxemburger C, Hkirjaroen L, terKuile F, et al. Factors contributing to anemia after uncomplicated falciparum malaria. Am J Trop Med Hyg 2001; 65:614-22. https://doi. org/10.4269/ajtmh.2001.65.614

5. Clark IA, Hunt NH. Evidence for reactive oxygen intermediates causing hemolysis and parasite death in malaria. Infect Immun 1983; 39:1-6. https://doi.org/10.1128/IAI.39.1.1-6.1983

6. Facer CA, Bray RS, Brown JC. Direct Coombs antiglobulin reaction in Gambian children with Plasmodium falciparum malaria. I. Incidence and class specificity. Clin Exp Immunol 1997; 35:119-27.

7. Das BS, Nanda NK. Evidence for erythrocyte lipid peroxidation in acute falciparum malaria. Trans R Soc Trop Med Hyg 1999; 93:58-62. https://doi. org/10.1016/S0035-9203(99)90180-3

8. Clark IA, Chaudri C. Tumor necrosis factor may contribute to the anaemia of malaria by causing dyserythropoesis and erythrophagocytosis, $\mathrm{Br} J$ Haematol 1988; 70:99-103. https://doi. org/10.1111/j.1365-2141.1988.tb02440.x

9. Kurtzhals JA, Adabayeri V, Goka BQ, Akanmori BD, Oliver-Commey JO, Nkrumah FK, et al. Low plasma concentrations of interleukin 10 in severe malarial anemia compared with cerebral and uncomplicated malaria. Lancet 1998; 351:1762-72. https://doi.org/10.1016/S0140-6736(97)09439-7

10. Kurtzhals JA, Rodrigues O, Addae M, Commey JO, Nkrumah FK, Hviid L. Reversible suppression of bone marrow response to erythropoietin in Plasmodium falciparum malaria. $\mathrm{Br} \mathrm{J}$ Haematol 1997; 97:169-74. https://doi.org/10.1046/j.13652141.1997.82654.x

11. Maciejewski JP, Selleri C, Sato T, Cno HG, Keefer LK, Nathan CF, et al. Nitric oxide suppression of human hematopoiesis in vitro. Contribution to inhibitory action of interferon-gamma and tumor necrosis factor-alpha. J Clin Invest 1995; 96:108592. https://doi.org/10.1172/JCl118094

12. De Sousa K, Silva MS, Tavira LT. Variation of nitric oxide levels in imported Plasmodium falciparum malaria episodes. African J Biotechnol 2008; 7:799.

13. Domachowske JB. The role of nitric oxide in the regulation of cellular iron metabolism. Biochem Mol Med 1997; 60:1-7. https://doi.org/10.1006/ bmme.1996.2557

14. Anstey NM, Granger DL, Hassanali MY, Mwaikambo ED. Nitric oxide, malaria and anemia: inverse relationship between nitric oxide production and hemoglobin concentration in asymptomatic, malaria-exposed children. Am J Trop Med Hyg 1999; 6:249-52. https://doi.org/10.4269/ ajtmh.1999.61.249

15. Pradhan P. Malarial anaemia and nitric oxide induced megaloblastic anaemia: a review on the causes of malarial anaemia. J Vector Borne Dis 2009; 46:100-8.

16. Grau GE, Taylor TE, Molyneux ME, Wirima JJ, Vassalli P, Hommel M, et al. Tumor necrosis factor and disease severity in children with falciparum malaria. N Engl J Med 1989; 320:1586. https:// doi.org/10.1056/NEJM198906153202404 
17. Kurtzhals JA, Helleberg M, Goka BQ, Akanmori BD. Severe malaria in West African children. Lancet 2003; 361:1393. https://doi.org/10.1016/ S0140-6736(03)13068-1

18. Nkrumah FK. Severe anaemia associated with malaria in children. Ghana Med J 1973; 12:17-21.

19. Mirdha BR, Samantray JC, Mishra B, Xess I. Bone-marrow examination for identifying malaria in fever of unknown origin. J Assoc Physicians India 1999; 47:177-9.

20. Tatura SNN, Gunawan S, Bernadus J, Sandjoto S. Plasmodium falciparum found in the bone marrow of a child in Manado City, East Indonesia: a case report. Asian Pac J Trop Med 2017; 10:1015-7. https://doi.org/10.1016/j.apjtm.2017.09.016

21. Tjitra E, Suprianto S, McBroom J, Currie BJ, Anstey NM. Persistent ICT malaria P.f /P.v pan malarial and HRP2 antigen reactivity after treatment of Plasmodium falciparum malaria is associated with gametocytemia and results in false-positive diagnoses of Plasmodium vivax in convalescence. J Clin Microbiol 2001; 39:1025-31. https:// doi.org/10.1128/JCM.39.3.1025-1031.2001

22. Piper R, Lebras J, Wentworth L, Hunt-Cooke A, Houze S, Chiodini P, et al. Immunocapture diagnostic assays for malaria using Plasmodium lactate dehydrogenase. Am J Trop Med Hyg 1999, 60:109-18. https://doi.org/10.4269/ ajtmh.1999.60.109

23. Autino B, Corbett Y, Castelli F, Taramelli D. Pathogenesis of malaria in tissues and blood. Mediterr J Hematol Infect Dis 2012; 4: e2012061. https:// doi.org/10.4084/mjhid.2012.061

24. Aggarwal V, Maheshwari A, Rath B, Kumar P, Basu $\mathrm{S}$. Refractory pancytopenia and megaloblastic anemia due to falciparum malaria. J Trop Ped 2011; 57:283-5. https://doi.org/10.1093/tropej/ fmq090

25. Vinoth PN, Thomas KA, Selvan SM, Suman DFR, Scott JX. Hemophagocytic syndrome associated with falciparum infection. Indian J Pathol Microbiol 2011; 54:594-6. https://doi.org/10.4103/03774929.85105

26. Helleberg M, Goka BQ, Akanmori BD, Obeng-Adjei G, Rodriques O, Kurtzhals JA. Bone marrow suppression and severe anaemia associated with persistent Plasmodium falciparum infection in African children with microscopically undetectable parasitaemia. Malar J 2005; 4:56. https://doi. org/10.1186/1475-2875-4-56

CONFLICT OF INTEREST
Authors declare no conflict of interest.
GRANT SUPPORT AND FINANCIAL DISCLOSURE
None declared.

\section{AUTHORS' CONTRIBUTION}

The following authors have made substantial contributions to the manuscript as under:

Conception or Design: $\quad$ ZH, IU, HAK, FR

Acquisition, Analysis or Interpretation of Data: $\quad$ ZH, IU, KH, HAK, FR, HK

Manuscript Writing \& Approval: $\quad$ ZH, IU, KH, HAK, FR, HK

All the authors agree to be accountable for all aspects of the work in ensuring that questions related to the accuracy or integrity of any part of the work are appropriately investigated and resolved. stricted use, distribution \& reproduction in any medium provided that original work is cited properly.
} 